\title{
PROTEÇÃO SOCIAL E DESIGUALDADE NO BRASIL
}

\section{SOCIAL PROTECTION AND INEQUALITY IN BRAZIL}

\section{RESUMO}

O trabalho analisa o alcance das políticas de proteção social, em especial da Previdência Social e da Assistência Social, no enfrentamento da desigualdade de renda no Brasil. Embora se tenha observado uma queda acelerada da desigualdade de renda na última década, o Brasil ainda se encontra entre os países que apresentam os maiores índices de desigualdade do mundo. Nesse contexto, as políticas de proteção social exercem um papel fundamental no enfrentamento da pobreza e da desigualdade de renda. Entretanto, observa-se que tais políticas podem, também, causar um efeito perverso, contribuindo para a reprodução e o aumento das desigualdades existentes na sociedade. Diante de tal realidade, busca-se apontar, de um lado, as iniciativas bem-sucedidas no âmbito da proteção social, no que se refere ao enfrentamento da desigualdade de renda, e por outro, as deficiências do sistema, de modo a identificar possíveis caminhos de mudança.

PALAVRAS-CHAVE Desigualdade de renda, Previdência Social, Assistência Social, proteção social, Brasil.

Mariana Eugenio Almeida mariana.almeida88@gmail.com

Graduada em Ciências Sociais pela Universidade Federal de Minas Gerais (2010); mestranda em Administração Pública pela Fundação João Pinheiro (FGP)

Artigo submetido no dia 26.09.2011 e aprovado em 31.07.2012

\begin{abstract}
The paper analyzes the scope of social protection policies, especially of the Social Security and Social Services, in facing income inequality. Although there has been an accelerated reduction on income inequality over the last decade, Brazil is still among the countries with the highest rates of inequality in the world. In this context, social protection policies play an important role in facing poverty and income inequality. However, such policies may also cause a perverse effect, contributing to the reproduction and the increase of the inequalities in society. Thus, we aim to point out on the one hand, successful initiatives in the framework of social protection, when facing income inequality and, secondly, the deficiencies of the system in order to identify possible paths of change.
\end{abstract}

KEYWORDS Income inequality, Social Security, social services, social protection, Brazil. 


\section{INTRODUÇÃO}

O Brasil se encontra hoje entre os países que apresentam os maiores índices de desigualdade de renda do mundo. Embora se tenha observado uma queda acelerada dessa desigualdade a partir de 2001, fazendo com que o Brasil tenha se revelado um dos países com maior potencial de redução da desigualdade nos últimos tempos (BARROS et al., 2006b), a grande concentração de renda ainda consiste em um grave problema do país.

Nesse contexto, observa-se que o governo brasileiro tem aplicado um grande volume de recursos na área de políticas sociais, em especial no que se refere ao enfrentamento da pobreza e da desigualdade. Pode-se dizer que há hoje no Brasil um sistema de proteção social que exerce influência direta sobre esses indicadores. Por "proteção social" entende-se aqui

[...] um conjunto de políticas e programas governamentais destinado à prestação de bens e serviços e à transferência de renda, com o objetivo de cobertura de riscos sociais, garantia de direitos sociais, equalização de oportunidades e enfrentamento das condições de destituição e pobreza. (CARDOSO JR.; JACCOUD, 2005, p. 194).

No entanto, é necessário analisar o verdadeiro alcance de tais políticas, uma vez que elas podem apresentar efeitos perversos. Dessa forma, o problema de pesquisa que será investigado neste trabalho é o impacto que determinadas políticas de proteção social podem exercer sobre a distribuição de renda em uma sociedade. Optou-se por analisar apenas as políticas de Previdência Social e Assistência Social, por elas exercerem efeitos diferenciados sobre a distribuição de renda no Brasil. Assim, nosso objetivo geral é analisar em que medida um sistema de proteção social pode contribuir para a reprodução, aumento ou queda da desigualdade de renda em uma sociedade. Mais especificamente, pretende-se analisar como, por um lado, as políticas de Previdência Social e de Assistência Social, enquanto parte de um sistema de proteção social, podem contribuir para a redução da desigualdade de renda. Por outro lado, discute-se como tais políticas podem, também, exercer um efeito perverso, ou seja, contribuir para reforçar tal desigualdade, reproduzindo-a e até mesmo aumentando-a.

Nesse contexto, se de um lado se ressaltam as iniciativas bem-sucedidas, por outro se apontam, também, as deficiências do sistema, de modo a identificar possíveis caminhos de mudança. Trata-se de um trabalho qualitativo, ou seja, a metodologia utilizada contou com uma análise crítica e reflexiva das políticas de Previdência Social e Assistência Social no Brasil, no que diz respeito à sua capacidade redistributiva, baseando-se em dados secundários e revisão bibliográfica.

O texto está organizado em quatro seções, a contar com esta introdução. Na seção 2, traça-se um breve panorama da desigualdade de renda no Brasil, ressaltando a queda recente desse indicador. Na seção 3, é feita uma análise crítica do sistema de proteção social brasileiro - em especial no que se refere às políticas de Previdência Social e Assistência Social - nos períodos anterior e posterior à Constituição Federal de 1988, apontando as características de tais políticas que podem contribuir para a diminuição, reprodução ou aumento da desigualdade de renda. Por fim, a seção 4 traz algumas considerações finais.

\section{DESIGUALDADE DE RENDA NO BRASIL}

A presente análise busca discutir a desigualdade de renda no Brasil. Observa-se que tanto a desigualdade de renda resultante de fatores educacio- 
nais como a resultante de fatores relacionados ao mercado de trabalho dizem respeito, principalmente, à renda proveniente do salário. Entretanto, a desigualdade de renda total é composta por diferentes fontes de renda, dentre as quais a renda advinda de programas de transferências governamentais. Segundo Ferreira et al. (2006), no Brasil, tem crescido a importância das rendas provenientes das transferências de seguridade social e das "outras rendas" no enfrentamento à desigualdade total.

É possível identificar três períodos distintos no que se refere ao comportamento das medidas de desigualdade no Brasil (FERREIRA et al., 2006). Observa-se, primeiramente, entre 1981 e 1989, uma elevação significativa de todas as medidas de desigualdade, com o índice Gini passando de 0,58 em 1981 ao seu ponto máximo de 0,63 em 1989. É importante ressaltar que o aumento observado entre 1988 e 1989 é muito acentuado, fato ainda obscuro entre os estudiosos, podendo ter sido proporcionado pela alta inflação observada no período, que pode ter comprometido as estimativas (RAMOS; VIEIRA, 2001). O período seguinte, que vai de 1989 a 1993, é marcado por uma relativa queda, voltando os indicadores a crescer por volta de 1992. Por fim, de 1994 a 2009, há uma queda quase que contínua da desigualdade, mais acentuada a partir de 2002, chegando o índice de Gini a atingir o seu menor valor $(0,54)$ no ano de 2009 (IPEADATA, 2012).

Ao se ordenar a população de acordo com a renda per capita e dividi-la em 10 partes iguais, observa-se que a renda da fatia $10 \%$ mais pobre auferiu um ganho real de 69,08\%, quando se compara a PNAD de $2009 \mathrm{com}$ a de 2001 (NERI, 2011 , p. 9). No mesmo período, o ganho foi menor nas faixas de renda mais altas, sendo de $12,58 \%$ na parcela $10 \%$ mais rica.

De acordo com Neri (2011), a parcela da renda apropriada pela metade da população mais pobre teria crescido a uma taxa 318\% mais alta do que a dos 10\% mais ricos entre 2001 e 2009 (NERI, p. 9). Pode-se dizer que o período analisado foi relativamente favorável à parcela mais pobre da população. Observa-se, portanto, que o Brasil experimentou, na última década, um declínio da desigualdade de renda, que tem contribuído substancialmente para reduzir a pobreza e melhorar as condições de vida da população mais vulnerável (BARROS et al., 2006a, HOFFMANN, 2006; SOARES et al., 2006).

Estudos diversos vêm tentando identificar os fatores determinantes da queda recente da desigualdade no Brasil. Segundo o estudo realizado pelo IPEA (2006), podem-se identificar três fatores importantes para a análise dessa queda: a) o aumento da renda proveniente do trabalho, resultado das transformações observadas na dinâmica do mercado de trabalho e na heterogeneidade educacional; b) as transformações por que passaram os diversos tipos de transferências de renda governamentais e; c) o aumento do salário mínimo.

No que diz respeito ao papel reprodutor de desigualdades do mercado de trabalho, observa-se que a última década no Brasil foi marcada por significativos progressos educacionais, o que contribuiu de forma expressiva para a queda da desigualdade de renda (RAMOS, 2006). Já em relação ao papel do mercado de trabalho na geração de desigualdades, observa-se uma redução no seu grau de discriminação e segmentação, o que também vem contribuindo para explicar a queda da desigualdade de renda no Brasil. Entretanto, a segmentação formal-informal estaria agindo como uma força contrária à queda da desigualdade de renda (BARROS et al., 2006b).

Observa-se, ainda, que a contribuição dos programas de transferência de renda para a redução da desigualdade de renda é crescente (HOFFMANN, 2006; BARROS et al., 2006b; SOARES et al., 2006). Segundo Rocha (2006), essa contribuição vem sendo favorecida pelo aumento da 
cobertura e da focalização desses programas. Outro fator importante é o salário mínimo, que no Brasil está relacionado com as rendas de aposentadorias e pensões, e de alguns programas sociais (SABOIA, 2006). Isso ocorre porque o salário mínimo foi estabelecido como piso do sistema previdenciário no Brasil, além de determinar o valor do Benefício de Prestação Continuada.

Em suma, independentemente dos fatores explicativos escolhidos, observa-se que, desde 2001, o Brasil vem apresentando uma queda de desigualdade de renda acelerada. Ainda assim, o país apresenta índices de desigualdade de renda extremamente elevados, o que comprova que o avanço recente constitui apenas o início de um grande caminho a ser percorrido. Some-se a isso o fato de estudos mostrarem evidências de uma desaceleração da queda da desigualdade nos últimos anos, de modo que a redução observada em 2005 foi muito menor do que a observada no ano anterior (BARROS et al., 2006b; HOFFMANN, 2006).

\section{0 SISTEMA DE PROTEÇÃO SOCIAL E SUAS IMPLICAÇÕES PARA A DISTRIBUIÇÃO DE RENDA NO BRASIL}

A análise do processo de formação e desenvolvimento das políticas de proteção social revela que elas podem favorecer ou combater a desigualdade de renda. A provisão de serviços sociais pelo Estado é um fenômeno que se desenvolveu em diversos países, em especial a partir do século XX. Ao conjunto de políticas que tinham como objetivo cobrir os riscos sociais foi dado o nome de Welfare State ou Estado de Bem-Estar Social. Segundo Esping-Andersen (1990), os diferentes tipos de regimes de bem-estar podem gerar diferentes tipos de estratificação social. Assim, o autor as- sinala que "o Estado de Bem-Estar Social não é somente um mecanismo que intervém e possivelmente corrige a estrutura das desigualdades; constitui, em si mesmo, um sistema de estratificação. É uma força ativa no ordenamento das relações sociais" (ESPING-ANDERSEN, 1990, p. 23).

No caso do Brasil, estudos que buscam avaliar o impacto das transferências previdenciárias e assistenciais apontam que, na ausência de tais transferências, os níveis de indigência e pobreza no país aumentariam significativamente (JACCOUD, 2009). Entretanto, algumas políticas podem causar efeitos perversos, contribuindo, inclusive, para o aumento da desigualdade de renda. Dessa forma, esta seção pretende analisar o papel das políticas de Previdência Social e Assistência Social no combate à desigualdade de renda no Brasil.

\subsection{PROTEÇÃO SOCIAL NO PERÍODO ANTERIOR À CONSTITUIÇÃO DE 1988: A CONSTRUÇÃO DE UMA CIDADANIA QUE DIFERENCIA OS CIDADÃOS}

Em grande medida, a literatura considera como marco inicial da política de Previdência Social no Brasil a promulgação da Lei Elloy Chaves, em 1923, que cria as Caixas de Aposentadorias e Pensões (CAPs). Entretanto, não se pode falar nessa época de um sistema de proteção social consolidado, pois a interferência do poder público nas instituições previdenciárias na década de 1920 era muito restrita. Podemos dizer que as CAPs representam o início do desenvolvimento, no Brasil, de um modelo de proteção social que se assemelha ao modelo residual de Richard Titmuss (1974), uma vez que as políticas sociais públicas ocupavam, nesse período, um papel mínimo na provisão de bem-estar. O efeito redistributivo desse modelo é muito pequeno, pois ele tende a favorecer aqueles que podem pagar e deixa desprotegido todo o restante da população, contri- 
buindo, assim, para a reprodução das desigualdades já existentes na sociedade.

A partir dos anos 1930, observa-se que, com a criação dos Institutos de Aposentadorias e Pensões (IAPs), o modelo se torna mais corporativo, mas continua centrado em um princípio bismarckiano, ${ }^{1}$ com uma política contributiva e excludente, conservando, assim, características que contribuem para aumentar a concentração de renda. A Previdência realizada por meio dos IAPs tornou-se um instrumento de incorporação controlada, de modo que detinha o poder de definir quem teria acesso à cidadania. Dada tal configuração do sistema previdenciário, Santos (1979) ressalta o conceito de cidadania regulada. Segundo o autor, seriam cidadãos todos aqueles que fizessem parte de categorias profissionais "reconhecidas e definidas em lei". Eram "pré-cidadãos" aqueles que não tinham profissão reconhecida pelo Estado, ou seja, todos os trabalhadores da área rural, bem como os trabalhadores urbanos, cujas ocupações não eram reguladas por lei.

Observa-se, portanto, que esse arranjo teria favorecido a reprodução das desigualdades sociais presentes no país, não só por excluir grande parte da população do acesso a direitos sociais, mas também por garantir benefícios desiguais entre as categorias profissionais. Some-se a isso o fato de os benefícios concedidos resultarem de uma espécie de conquista de cada categoria profissional, o que favorecia o corporativismo no mundo sindical. Assim, o sistema previdenciário, tal como foi estruturado na década de 1930, não causou efeitos redistributivos significativos. A redistribuição de renda se dava apenas em termos horizontais, uma vez que as transferências ocorriam dentro de cada categoria profissional, representadas pelos IAPs. Além disso, o sistema fiscal brasileiro apresentava efeitos regressivos, proporcionados pelo caráter excludente do sistema previdenciário. ${ }^{2}$

A partir do final da década de 1960, ocorre o que Vianna (1998) chama de americanização perversa da previdência social. Nesse período, o sistema se estatiza e incorpora novas categorias profissionais, mas, em vez de hierarquizar a cidadania, ele a nivela num estatuto inferior. Isso ocorre porque a cobertura previdenciária se universaliza sob um ordenamento político fechado, que repreende as demandas sociais (VIANNA, 1998). Nesse sentido, Vianna (1998) defende a tese de que, ainda que com as tentativas de reformas, o modelo de proteção social brasileiro foi se tornando cada vez mais americano, pois as provisões públicas se restringiam a poucos benefícios aos pobres, cabendo ao mercado a oferta de benefícios àqueles que podem pagar.

Assim, permaneceu o caráter bismarckiano, predominantemente contributivo do sistema, de modo que as injustiças e desigualdades presentes na sociedade continuavam sendo reproduzidas. Segundo Boschetti (2006), o modelo contributivo constitui um paradoxo, uma vez que, em uma sociedade marcada pelas relações de trabalho não assalariadas e informais, eram protegidos apenas aqueles que tinham emprego e salário estáveis. Boschetti (2006, p. 65) chama a atenção para o fato de que "em um país onde o exercício de uma profissão não é acompanhado, necessariamente, pela formalização das relações de trabalho, seria um despropósito condicionar o acesso a esses direitos à existência de uma carteira de trabalho assinada". Nesse sentido, a lógica de cobertura do sistema previdenciário baseada na contribuição se manteve, em um país onde a sociedade salarial jamais se consolidou (CASTEL, 1995 apud BOSCHETTI, 2006).

Observa-se, portanto, que o período anterior à Constituição de 1988 (CF/88) foi marcado por uma política social residual e complementar ao mercado. Assim, poder-se-ia afirmar que o sistema de proteção social brasileiro, tal como foi estruturado, não teve como objetivo inicial atingir uma maior igualdade por meio das políticas sociais. O que se observa, ao menos até a década 
de 1980 no Brasil, é uma tentativa de proteção do status já adquirido pelo trabalhador contra os riscos sociais (AURELIANO; DRAIBE, 1989).

No que se refere à Assistência Social, é importante ressaltar que até a década de 1980 não era possível falar de uma política pública nessa área, o que contribuía para reforçar a desigualdade entre os cidadãos e os "pré-cidadãos", que continuavam desprotegidos. A Assistência Social no período anterior à CF/88 se encontrava principalmente sob a responsabilidade da iniciativa privada, em especial das instituições religiosas. Nesse contexto, no período que vai até a década de 1980 ,

\section{[...] falar da Assistência Social no Brasil significava falar de uma ação residual, suplementar em termos de recursos, fragmentada em termos de programas e ações e pouco clara quanto aos seus objetivos e ao seu público. (JACCOUD et al., 2009, p. 178).}

Os benefícios e serviços assistenciais eram associados mais à ideia de caridade do que à de um direito a ser assegurado pelo Estado. É somente com a CF/88 que a Assistência Social é reconhecida enquanto uma política pública e passa a ser norteada pelo princípio da solidariedade. O reconhecimento dessa área enquanto política contribui para a criação de programas que visam o enfrentamento da desigualdade e da pobreza, com será visto adiante.

\subsection{A POLÍTICA SOCIAL NA CONSTITUIÇÃO DE 1988 E SUAS IMPLICAÇÕES PARA A DISTRIBUIÇÃO DE RENDA NO BRASIL: OS PASSOS PARA UM MODELO DE PROTEÇÃO SOCIAL BASEADO EM SOLIDARIEDADE}

Pode-se dizer que a CF/88 representa um marco para a história das políticas sociais no Brasil, tanto no que se refere à reestruturação e ampliação dessa área como na diversificação de benefícios sociais, uma vez que ela inaugura um novo modelo de proteção social no Brasil, introduzindo conceitos e princípios antes inexistentes. Dentre eles, destacam-se o conceito de Seguridade Social e o princípio da solidariedade nacional, que passou a nortear a nova política de proteção social brasileira.

Considera-se que uma das mais importantes inovações do texto constitucional no âmbito da política social foi a definição do conceito de Seguridade Social enquanto organizador da proteção social brasileira. Esse conceito compreende "um conjunto integrado de ações de iniciativa dos Poderes Públicos e da sociedade, destinadas a assegurar os direitos relativos à saúde, à previdência e à assistência social" (BRASIL, 1988).

Dentre todas as inovações trazidas com o estabelecimento da Seguridade Social, destacam-se quatro que são diretamente relevantes para se pensar o impacto das políticas de proteção social na redistribuição de renda: o estabelecimento de uma proteção social não contributiva, portanto baseada em solidariedade nacional; o estabelecimento da saúde enquanto direito universal; a mudança da base de financiamento; e a vinculação de alguns benefícios ao salário mínimo. Essas mudanças representam a introdução de um novo paradigma na proteção social brasileira, que passa a se ancorar em três pilares: a política contributiva, a não contributiva e a universal. Esse conjunto de políticas contribui para a formação de sistema de proteção social brasileiro mais eficiente no enfrentamento da desigualdade de renda, ainda que permaneçam algumas limitações.

No que se refere ao estabelecimento de uma proteção social não contributiva, ressalta-se o reconhecimento da Assistência Social enquanto uma política pública. Isso possibilitou que fossem estabelecidas ações governamentais focalizadas de combate à pobreza e à desigualdade de renda, que passaram a beneficiar um público anteriormente descoberto. Pela primeira vez no Brasil surgem programas de transferência de renda destinados à população pobre e que não exigem 
comprovação de incapacidade para o trabalho ou de afirmação de mérito (JACCOUD, 2009). Além disso, é estabelecida uma política de proteção social universal e garantida por lei, como é o exemplo da saúde.

A criação de um orçamento próprio da Seguridade Social, com fontes diferenciadas de financiamento, possibilita o estabelecimento de uma proteção social que não é estritamente contributiva, o que favorece a população mais pobre, incapaz de contribuir. Essa inovação representa a superação do modelo bismarckiano, baseado na contribuição, e possibilita a estruturação de uma proteção social mais sólida e abrangente. No que se refere à vinculação de alguns benefícios ao salário mínimo, observa-se que essa inovação impossibilita situações de benefícios irrisórios como o foi a Renda Mensal Vitalícia, nas décadas de 1970 e 1980. Isso contribui para o estabelecimento da noção de garantia de uma renda mínima, que é essencial no enfrentamento da pobreza e da desigualdade de renda.

Portanto, mais do que a ampliação das políticas do sistema de Seguridade Social, a Constituição Federal estabelece as bases para um amplo sistema de proteção social no país (DELGADO et al., 2009). Nesse sentido, a CF/88 transforma o paradigma anterior na proteção social brasileira, uma vez que introduz o conceito de Seguridade Social. Se antes da década de 1980 havia uma proteção social centrada na Previdência e restrita no que se refere à cobertura e às bases de financiamento, após a $\mathrm{CF} / 88$ temos a garantia da saúde enquanto direito universal, da Assistência Social enquanto uma política não contributiva e da Previdência Social enquanto política contributiva. Temos, portanto, uma proteção social mais ampla, capaz de atingir uma maior parcela da população.

\subsection{PERÍOdo Pós-CONSTITUIÇÃO DE 1988: COMO AS DETERMINAÇÕES}

\section{CONSTITUCIONAIS ESTRUTURARAM UM NOVO PARADIGMA DE PROTEÇÃO SOCIAL NO BRASIL}

No período pós $\mathrm{CF} / 88$, observa-se o movimento de superação da "cidadania regulada". A consolidação do sistema de proteção social brasileiro possibilitada pelo texto constitucional favorece a inclusão dos "novos cidadãos", o que minimiza as desigualdades presentes em nossa sociedade, em especial a de renda. Entretanto, permanecem algumas distorções em nosso modelo, em especial no campo da Previdência Social, que contribuem para a reprodução e até mesmo o aumento dessas desigualdades. Considera-se, portanto, que o modelo de proteção social que temos hoje no Brasil é paradoxal, pois pode causar efeitos perversos na distribuição de renda da população, como veremos a seguir.

\subsubsection{DESENVOLVIMENTO DE UMA PERVERSA PREVIDÊNCIA SOCIAL}

Com a promulgação da CF/88, a Previdência Social passou a fazer parte do Sistema de Seguridade Social, avançando na busca da participação social e no combate às desigualdades socioeconômicas (RANGEL et al., 2009). Entretanto, uma análise reflexiva da Previdência Social no período pós $\mathrm{CF} / 88$ nos permite identificar o desenvolvimento de uma política perversa. Se de um lado o período é marcado pela introdução de medidas no sentido de aumentar a cobertura do sistema e diminuir as desigualdades presentes na nossa sociedade, de outro, a política conserva certas características que contribuem para o aumento da desigualdade de renda, como será visto a seguir.

Uma Previdência Social minimizadora de desigualdades: a Previdência Rural e a inclusão via incentivos econômicos

A Previdência Social, enquanto parte de um sistema de proteção social, pode exercer um efeito po- 
sitivo sobre a distribuição de renda. No caso brasileiro, destacam-se dois fatores que contribuem para a minimização das desigualdades: a criação da Previdência Rural, que permitiu a ampliação da cobertura do sistema; e a criação de incentivos econômicos destinados aos trabalhadores autônomos.

Uma das mudanças mais significativas trazidas com o texto constitucional se deu para os trabalhadores rurais, que passaram a ter tratamento equivalente ao dos trabalhadores urbanos. Os valores dos benefícios aumentaram e a idade mínima para requerimento do benefício diminuiu. Nesse sentido, as chamadas Previdência Social Urbana e Previdência Social Rural foram extintas, dando lugar ao Regime Geral de Previdência Social (RGPS). Com a criação da figura do segurado especial, ${ }^{3}$ o sistema deu um passo no sentido da ampliação da cobertura previdenciária. Pode-se dizer que essa nova categoria de segurado é regida pelos princípios beveridgianos, ${ }^{4}$ ou seja, não é necessário contribuição para que se tenha acesso ao benefício.

A CF/88, ao alterar os critérios de elegibilidade para a aposentadoria dos trabalhadores rurais, representa um avanço no processo de ampliação da cobertura previdenciária no Brasil. A unificação dos regimes possibilitou que fosse considerado o tempo de trabalho no campo para a aposentadoria na cidade. Essa conquista foi muito importante para mais da metade dos trabalhadores brasileiros, que apresentam uma trajetória de migração do meio rural para o urbano. Mas a inovação mais significativa para a população rural trazida com a CF/88 foi o fato de que agora é possível haver mais de um beneficiário por família. Com isso, todas as pessoas com mais de 16 anos que trabalham sob o regime de economia familiar passam a ser elegíveis à Previdência Social, e não apenas o chefe da família.

Podemos afirmar, portanto, que, ao estabelecer regras específicas para a Previdência Rural, a CF/88 quebra com o paradigma anterior, centrado em um sistema previdenciário estritamente contributivo, e introduz um novo paradigma: o da proteção social não contributiva. Diante da realidade laboral brasileira, na qual há uma desigualdade de renda entre os trabalhadores rurais e urbanos, considera-se que essas medidas contribuem para minimizar tais desigualdades.

No que se refere à cobertura do sistema, observa-se que o mercado de trabalho brasileiro, marcado pela informalidade, constitui um desafio. No sentido de promover uma maior inclusão, foi aprovada em 1996 a lei que criou o Sistema Integrado de Pagamento de Impostos e Contribuições das Microempresas e das Empresas de Pequeno Porte (Simples). Esse sistema possibilitou a inclusão de micro e pequenas empresas, estabelecendo um pacote tributário diferenciado e simplificado. O número total de empregados em estabelecimentos que optaram pelo sistema simplificado passou de 3,6 milhões em 1999 para 5,8 milhões em 2005, o que comprova a importância dessa medida para o aumento da cobertura previdenciária no Brasil (RANGEL et al, 2009). Mais recentemente, em 2006, foi instituído o Super Simples ou Simples Nacional, que estabelece normas gerais relativas à tributação diferenciada das micro e pequenas empresas no âmbito da União, dos estados e municípios, mediante um regime único de arrecadação. Tal regime passou a substituir o Simples em 2007.

Ainda em relação aos incentivos voltados a empresas, em 2008 foi aprovada a lei que criou a figura do microempreendedor individual (MEI), destinada a micronegócios, com faturamento de até R\$ 3 mil mensais. Entretanto, havia ainda um grupo de difícil inclusão no sistema previdenciário, os trabalhadores por conta própria, estudantes e donas de casa. Assim, foi criado o Plano Simplificado de Previdência Social (PSPS), que estabelece uma alíquota reduzida para o contribuinte individual e o segurado facultativo do 
INSS.

A inclusão via incentivos econômicos objetiva tornar a Previdência Social mais acessível "à população que se encontra na franja do mercado de trabalho, e, ao mesmo tempo, reforçar que só está incluído quem contribui para o sistema" (RANGEL et al., 2009). Entretanto, o mercado de trabalho brasileiro, fortemente marcado pela atividade informal, ainda consiste em um dos maiores desafios para a Previdência Social brasileira. Podemos dizer, portanto, que as medidas destinadas aos trabalhadores rurais trazidas com a CF/88 foram as que causaram o maior efeito sobre a cobertura previdenciária. As demais políticas podem também ser consideradas inclusivas, mas não causam efeitos facilmente observáveis, pois dependem mais da ação dos empregadores e dos trabalhadores do que do governo (RANGEL et al., 2009). Além disso, o contexto econômico e do mercado de trabalho exercem grande influência sobre a decisão de filiar-se ao sistema previdenciário.

Uma previdência social geradora de desigualdades: os diferentes regimes, suas regras de financiamento e a questão da informalidade Observa-se, portanto, que a política de Previdência Social exerce um papel fundamental no enfrentamento da pobreza e da desigualdade. $\mathrm{O}$ aumento da cobertura do sistema previdenciário e a vinculação do benefício ao salário mínimo contribuíram para o aumento da renda da parcela mais pobre da população e para a redução da desigualdade (MAIA, 2010). A despeito dos avanços alcançados em termos de cobertura com a criação da Previdência Rural e dos incentivos econômicos destinados aos trabalhadores autônomos, observa-se que a Previdência Social brasileira pode exercer um efeito perverso e contribuir para a reprodução e geração de desigualdades. Nesse sentido, destacam-se dois pontos fundamentais para a discussão sobre a desigualdade de renda no Brasil: a diferenciação dos regimes de previdência social e suas regras de financiamento, e o alto grau de informalidade do trabalho presente da sociedade brasileira.

Em relação à organização atual do sistema previdenciário brasileiro, observa-se que ele é estruturado em três pilares. Um deles é a chamada previdência básica, coberta pelo Regime Geral de Previdência Social (RGPS), de caráter obrigatório e sob a administração do Instituto Nacional do Seguro Social (INSS). Os beneficiados desse regime são os empregados do setor privado (regidos pela CLT), de empresas estatais, trabalhadores rurais inseridos no regime de economia familiar, bem como os trabalhadores por conta própria e os contribuintes avulsos.

Outro pilar da Previdência Social brasileira atual é o dos servidores públicos, cobertos pelos Regimes Próprios de Previdência Social (RPPS). Por meio destes, são beneficiados os servidores públicos civis e militares nos níveis federal, estadual e municipal. Esses regimes seguem os princípios gerais do Regime Jurídico Único (RJU), com exceção dos servidores militares. Esse pilar tem caráter compulsório e é de responsabilidade do Estado. Por fim, há o pilar da Previdência Complementar, de caráter voluntário, que concede benefícios opcionais complementares aos trabalhadores do setor privado.

A diferenciação da previdência em regimes distintos acabou por contribuir para a reprodução da desigualdade de renda no Brasil. Segundo Giambiagi e Além (1999), é possível identificar quatro privilégios dos funcionários públicos em relação aos segurados do INSS, até 1998: 1) no RGPS, até as reformas, a base de cálculo dos benefícios eram 36 remunerações observadas num período variável entre os 24 e 48 últimos meses de trabalho, já no RJU, o valor do benefício correspondia à última remuneração do servidor;5 2) no âmbito do RJU, há algumas categorias favorecidas, sendo o valor dos benefícios maior que o valor das contri- 
buições; 3) no RGPS, o benefício é limitado a um teto e condicionado a contribuições, já no RJU, a aposentadoria integral com base no último salário se dava sem cobrança de contribuição específica até 1993, sem a exigência prévia de uma carência adequada e sem a existência de um teto. Com as reformas, passou-se a exigir um período mínimo de carência de 10 anos, mantendo-se a integralidade e a base de cálculo dos benefícios; 6 4) os professores até as reformas tinham regimes especiais de aposentadoria. Esse grupo é estatisticamente mais significativo no quadro do funcionalismo público, em especial nos estados e municípios, o que acaba por onerar as contas públicas. Com as reformas, a aposentadoria especial acabou apenas para os professores universitários, sendo mantida para o ensino fundamental e o médio.

No que se refere ao financiamento, até a década de 1990 os servidores públicos civis da União contribuíam apenas para o benefício de pensão por morte. Foi apenas em 1993, com a Emenda Constitucional $\mathrm{n}^{\mathrm{o}} 3$, que o custeio das aposentadorias e pensões dos servidores públicos federais passou a ser realizado com recursos da União e de contribuições dos servidores. Em relação aos servidores públicos dos estados e municípios, abriu-se a possibilidade de criação de regimes próprios de previdência (RPPS). Tal fato gerou um grande volume de regras e regimes, estabelecidos por cada ente federado. Nesse contexto, observa-se que as diferenças entre o RGPS e o RJU acabaram por gerar desequilíbrios nos gastos da União, o que revela à disparidade existente entre o valor dos benefícios concedidos em ambos os regimes e contribui para aumentar a desigualdade entre esses dois grupos.

Nas décadas posteriores à $\mathrm{CF} / 88$, o volume de pagamentos de benefícios cresceu em um ritmo mais acelerado que o volume de recursos arrecadados por meio de contribuições (IPEA, 2006). Diversas reformas foram feitas, mas não se atingiu de fato uma isonomia entre os regimes. O RJU e o RGPS continuaram apresentando divergências, entre as quais temos: o benefício equivalente à última remuneração para o RJU, a existência de categorias favorecidas, como os militares, regime especial para professores do ensino médio e fundamental e a concessão de um leque maior de benefícios para o RJU. Observa-se, assim, que a diferenciação da previdência em regimes resulta em regras e benefícios distintos, o que contribui para o favorecimento de alguns grupos e gera concentração de renda.

Nesse sentido, estudos mostram que a renda proveniente das aposentadorias e pensões não atreladas ao salário mínimo pode causar um efeito perverso, resultando em um aumento da desigualdade. Ferreira e Souza (2008) demonstraram que as aposentadorias e pensões exerceram uma contribuição substantiva para a desigualdade de renda entre 1981 e 2001. Segundo os autores, algumas características do sistema previdenciário podem estar contribuindo para esse aumento da desigualdade, tais como: as aposentadorias por tempo de serviço, sem limitação de idade; e os altos valores de benefícios concedidos a uma pequena parcela da população, que não contribui com um valor adequado. Posteriormente, trabalho realizado por Hoffmann (2009) confirma o caráter regressivo das aposentadorias e pensões. Segundo o autor, tal fato se dá, basicamente, devido à dualidade do sistema previdenciário brasileiro, que estabelece normas especiais para os militares e funcionários públicos. Assim, no que se refere à Previdência Social brasileira, observa-se que o rendimento proveniente de aposentadorias e pensões de funcionários públicos e $\mathrm{o}$ rendimento da previdência privada estão entre as parcelas de renda que se destacam pelo caráter regressivo (HOFFMANN, 2010). Uma vez que os pagamentos realizados pelo INSS são progressivos e a cobertura da previdência privada é muito pequena, pode-se dizer que as aposentadorias e pensões pagas aos funcionários públicos são as 
que exercem o maior efeito regressivo (HOFFMANN, 2010).

Ainda no que diz respeito ao caráter gerador de desigualdades da Previdência Social brasileira, ressalta-se a questão da informalidade no mercado de trabalho. Com o texto constitucional, a cobertura do sistema previdenciário brasileiro aumentou significativamente. Entretanto, nota-se que a informalidade continua a exercer o maior peso quando nos referimos à população da PEA não contribuinte (RANGEL et al., 2009). Dessa forma, ainda há uma grande parcela da população desprotegida e que, além disso, possui empregos precários e rendas baixas, contribuindo para a realidade desigual no Brasil.

Segundo Rangel et al. (2009), o crescimento econômico acelerado, aliado às medidas de inclusão previdenciária via subsídios, pode ter sido responsável pela redução da informalidade e a ampliação da cobertura do sistema nos últimos anos. Entretanto, as medidas de incentivo à formalização analisadas podem se tornar marginais na ampliação da cobertura do sistema, uma vez que a informalidade é um problema estrutural do mercado de trabalho brasileiro (RANGEL et al., 2009). Apesar de ter sido observado um declínio dos níveis de informalidade nos últimos anos, observa-se que esse número sempre foi superior a $30 \%$, o que ainda representa uma grande parcela da população brasileira (IPEADATA, 2012).

Em suma, apesar de a Previdência Social ter avançado no sentido da ampliação da cobertura no período posterior à $\mathrm{CF} / 88$, há ainda um grupo descoberto pelo sistema, notadamente os trabalhadores informais, que mesmo com os incentivos econômicos oferecidos pelo governo não tem condições de se filiar ao sistema. Nesse sentido, considera-se que a informalidade é um dos principais desafios da Previdência Social brasileira. Por isso, é importante que as políticas previdenciárias venham acompanhadas de políticas voltadas para o mercado de trabalho, em especial no que se refere à formalização do trabalho.

\subsubsection{A CRIAÇÃO DE UMA ASSISTÊNCIA SOCIAL BASEADA NO PRINCÍPIO DA SOLIDARIEDADE}

No campo da Assistência Social, a CF/88 marcou o início de uma série de mudanças estruturais. Ao reconhecer a Assistência Social enquanto uma política pública, o texto constitucional inaugurou uma nova fase dessa política, introduzindo um novo princípio: o da solidariedade. A criação de uma política social baseada na solidariedade é fundamental no contexto de grande concentração de renda, como é o caso do Brasil. Nesse sentido, esta seção discute alguns fatores importantes no âmbito da Assistência Social para compreender a queda recente da desigualdade de renda no país.

Segundo Jaccoud et al. (2009), alguns aspectos do texto constitucional em relação à política assistencial devem ser destacados. Em primeiro lugar, a Assistência Social foi integrada ao conceito de Seguridade Social, reforçando o seu princípio de proteção social. O segundo aspecto se refere à garantia de benefícios a quem deles necessitarem, sem exigência de contribuição. Assim, a política assistencial se afirma no Brasil enquanto uma política não contributiva baseada em solidariedade nacional. Observa-se que tal fato representa uma inovação no cenário da proteção brasileira, anteriormente caracterizado por sua base contributiva. O terceiro aspecto destacado diz respeito à instituição do Benefício de Prestação Continuada (BPC), destinado a idosos e deficientes impossibilitados de exercer atividade produtiva. Por fim, a CF/88 traz algumas modificações no que se refere à organização institucional, reforçando a descentralização da execução das tarefas.

A afirmação da responsabilidade do Estado para com a Política Assistencial trouxe desafios diversos. Nesse contexto é que a Lei Orgânica de Assistência Social (LOAS) foi aprovada, em 1993, 
definindo a Assistência Social como uma política que tem a função de prover mínimos sociais e delimitando as responsabilidades das três esferas de governo. Pode-se dizer que a LOAS contribui para superar a tradicional associação entre a assistência e o público incapaz de trabalhar, uma vez que vincula essa política à população em geral, empregada ou não, desde que em situação de necessidade. Além disso, a LOAS incorpora as políticas de transferência de renda ao campo não contributivo. Essas políticas interagem com as políticas contributivas do sistema de proteção social brasileiro, contribuindo para a ampliação da cobertura de um público excluído do sistema previdenciário (IPEA, 2007).

Foi a aprovação da Política Nacional de Assistência Social (PNAS), em 2004, que representou um verdadeiro marco para o estabelecimento de um novo modelo assistencial no Brasil. Nesse contexto, foi criado o Programa de Atenção Integral à Família (PAIF), que tem como objetivo "fortalecer a função de proteção das famílias, prevenindo a ruptura de laços, promovendo o acesso e usufruto de direitos e contribuindo para a melhoria da qualidade de vida" (MDS, 2012). Assim, o PAIF passou a nortear a política assistencial no Brasil, em especial no que se refere à prestação de serviços.

Observa-se, portanto, que a política assistencial após a CF/88 passou a ser organizada em duas vertentes: de um lado, foi criada uma estrutura de prestação de serviços; de outro, foram desenvolvidas políticas de transferências de renda. Destacaremos aqui as características principais dessas duas vertentes, que nos ajudam a pensar no papel da política assistencial no que diz respeito ao enfrentamento da desigualdade de renda no Brasil.

\section{- Estrutura de prestação de serviços}

No contexto da nova política assistencial foram criados equipamentos públicos responsáveis pela prestação de serviços à população, sendo eles os Centros de Referência em Assistência Social (CRAS) e os Centros de Referência Especializada de Assistência Social (CREAS). Nesse sentido, a política assistencial passou a ser operacionalizada em dois níveis: a Proteção Social Básica (PSB), realizada predominantemente no CRAS, e a Proteção Social Especial (PSE), realizada no CREAS. A PSB cumpre o papel de prevenir a população vulnerável quanto a situações de risco, envolvendo ações cujo foco é a família. A PSE, por sua vez, atende famílias e indivíduos que se encontram em situação de risco pessoal e social, como consequência de situações diversas, como abandono, maus tratos, trabalho infantil, abuso sexual ou situação de rua.

Observa-se, ainda, que a LOAS possibilitou a autonomia da União, estados, Distrito Federal e municípios, no que diz respeito à elaboração de sua própria política de Assistência Social. Atualmente, ao governo federal cabe a implementação e o financiamento de programas de segurança de renda. Já os municípios ficam responsáveis pela prestação de serviços, seja no âmbito da proteção básica ou especial. A estrutura de prestação de serviços assistenciais representa uma inovação nessa área, que anteriormente contava com ações pontuais, sem impacto efetivo. Agora, a Assistência Social passa a ser uma responsabilidade do Estado, possibilitando que os serviços assistenciais cheguem à população mais vulnerável em geral, que anteriormente era desprotegida, sem a exigência de contribuição.

- As políticas de transferência de renda: o BPC e o Bolsa Família

Nos últimos anos, o campo da Assistência Social vem sendo marcado pelas políticas de garantia de renda, dentre as quais podemos citar o Benefício de Prestação Continuada (BPC) e o Programa Bolsa Família (PBF). Apesar da crítica à expansão do Estado na área social e das restrições fiscais e orçamentárias enfrentadas, as políticas de garantia 
de renda se consolidaram no período pós-1988. Contudo, observa-se que

[...] a consolidação deste modelo depende não apenas de seus impactos diante da gravidade do quadro social brasileiro, mas também a um aprofundamento do debate sobre o papel das políticas de proteção social em projeto de sociedade menos desigual. (JACCOUD et al., 2009, p. 222).

Para compreender o efeito de tais políticas no combate à desigualdade de renda, apresentaremos como elas foram estruturadas, destacando-se o BPC e Programa Bolsa Família. No que se refere ao BPC, sua importância para o cenário da desigualdade de renda reside no fato de que ele constitui um direito e é regulamentado por lei. Dessa forma, esse benefício consiste em um dos pilares da mudança de paradigma trazida pela CF/88, uma vez que ele representa a proteção social não contributiva e reconhecida enquanto direito.

$O$ benefício, de natureza não contributiva, assume o valor de um salário mínimo e é destinado a idosos com 65 anos ou mais e pessoas com deficiência, incapacitados de trabalhar, cuja renda familiar per capita é inferior a um quarto de salário mínimo. É importante ressaltar que esse benefício é o primeiro mínimo social garantido constitucionalmente no Brasil e destinado a um público anteriormente excluído dos programas de garantia de renda.

Contudo, o BPC vem sendo alvo de discussões recentes, que se referem à natureza deste benefício e à sua função do campo da proteção social no Brasil. De um lado, estão aqueles que defendem uma reforma nas regras do BPC e argumentam que o benefício poderia significar um desestímulo à contribuição previdenciária, uma vez que não é vinculado a qualquer tipo de contribuição para a Previdência Social. Nesse sentido, assume-se o pressuposto de que trabalhadores jovens poderiam se afastar do setor formal da economia, com a expectativa de receber o BPC no futuro. Ainda contra o BPC, argumenta-se que nenhum benefício não contributivo deveria assumir o valor de um salário mínimo. Jaccoud (2009), por sua vez, defende que o BPC representa o campo da segurança de renda na proteção social brasileira. O BPC não substitui os benefícios previdenciários, mas sim, cobre um conjunto amplo de riscos sociais, beneficiando segmentos extremamente vulneráveis que antes não tinham nenhum tipo de proteção. Segundo Jaccoud et al. (2009, p. 207), a importância do BPC enquanto garantia de proteção social a grupos vulneráveis, anteriormente desprotegidos, deve ser ressaltada pois "é no espaço da Seguridade Social, e não no da Previdência Social, que o BPC efetiva sua proteção social. E, nesse sentido, também é no do fortalecimento do debate sobre a Seguridade Social que depende a consolidação do BPC". Dessa forma, entende-se que o problema da filiação previdenciária no Brasil não estaria ligado ao surgimento do BPC, mas sim à dinâmica do mercado de trabalho brasileiro, fortemente marcado pela precarização e informalidade.

Apesar das controvérsias, o número de beneficiários do BPC vem crescendo desde a sua implementação, em 1996, o que representa um avanço no que diz respeito à cobertura da proteção social no Brasil. Dados recentes do Ministério do Desenvolvimento Social e Combate à Fome mostram que, em outubro de 2010, 3.354 .816 pessoas eram atendidas pelo BPC, sendo 1.748.074 deficientes e 1.606.742 idosos. De acordo com Jaccoud et al. (2009), o BPC, bem como o RGPS e a Previdência Rural, teriam contribuído para que a pobreza e a indigência entre essa população sejam hoje consideradas fenômenos marginais. Segundo os autores, em 2007, cerca de 11,8\% dos idosos com mais de 65 anos no Brasil viviam com renda per capita de até meio salário mínimo, e apenas 1,4\% viviam com renda per capita até um quarto de salário mínimo. No caso da popula- 
ção deficiente, por enquanto é difícil identificar a proporção da cobertura desse benefício. Acredita-se ainda haver grande parcela da população deficiente elegível, que não tem acesso ao benefício.

No que se refere ao Programa Bolsa Família (PBF), observa-se sua crescente importância enquanto política de enfrentamento da pobreza e da desigualdade de renda no Brasil, possibilitando a consolidação do pilar não contributivo da proteção social brasileira. Em estudo realizado por Hoffmann (2010), dentre as parcelas de renda familiar analisadas, aquelas provenientes das transferências de programas sociais como o Bolsa Família foram as mais progressivas. Nesse contexto, verifica-se, nas últimas décadas, a criação de programas de transferência de renda condicionada, que exigem uma contrapartida do beneficiário, em geral que se comprometam com condições que beneficiem a si mesmos ou a sua família. O primeiro programa de transferência de renda condicionada federal foi criado em 1996, recebendo o nome de Programa de Erradicação do Trabalho Infantil (PETI). Nos anos seguintes, vários estados criaram programas semelhantes de transferência de renda.

O segundo programa de transferência de renda condicionada federal, o chamado Bolsa Escola Federal, foi criado no ano de 2001 e sucedido pelo Bolsa Alimentação e pelo Cartão Alimentação, criados em 2001 e 2003, respectivamente. Todos esses programas acabaram se desenvolvendo de forma desintegrada, constituindo "um emaranhado de iniciativas isoladas, com objetivos diferentes, porém sobrepostos, e para públicos diferentes, mas também sobrepostos" (SOARES; SÁTYRO, 2009, p. 12). Foi nesse contexto que o Programa Bolsa Família foi criado, no ano de 2003, pelo governo federal, com o objetivo de unificar o Bolsa Escola, o Bolsa Alimentação e o Cartão Alimentação, além do Vale-Gás.

O Bolsa Família é um programa que possui um orçamento definido e sua existência depen- de dele, não constituindo um direito, mas sim um benefício condicionado a possibilidades orçamentárias (SOARES; SÁTYRO, 2009). Tal fato constitui uma limitação do programa, pois, uma vez que não é um direito, pode ser alterado a qualquer momento e, inclusive, utilizado para fins políticos. O Bolsa Família é hoje considerado um importante instrumento de proteção social no Brasil, em termos de cobertura. Segundo Jaccoud et al. (2009, p. 216), a progressiva expansão do PBF nos últimos cinco anos "consolidou a transferência de renda não contributiva como um efetivo pilar da proteção social brasileira". Além disso, observa-se que, em termos de gastos, o Bolsa Família é responsável por uma pequena parcela do PIB, algo em torno de 0,3\% (SOARES; SÁTYRO, 2009). Nesse sentido, considera-se que o programa tem uma boa relação custo-benefício, uma vez que sua cobertura é extensa e os gastos são baixos.

No que se refere aos critérios de elegibilidade, o PBF é caracterizado pelo estabelecimento de duas linhas de pobreza, calculadas de acordo com a renda familiar per capita. ${ }^{7}$ Assim, para que se tenha acesso ao benefício, não é necessário comprovação de idade, incapacidade para o trabalho ou afirmação de mérito. O critério de elegibilidade é a renda, fazendo com que o programa seja focalizado na população mais pobre. Dessa forma, observa-se que o PBF também contribui para a superação da "cidadania regulada", uma vez que atinge uma população que, anteriormente, não tinha acesso à proteção social. Tornam-se "cidadãos" não apenas os desempregados, mas também os empregados, seja no mercado formal ou no informal, mas que não possuem renda suficiente para terem uma vida digna. Entretanto, o PBF revela, ainda, a incapacidade do mercado de trabalho brasileiro de garantir boas condições de vida, uma vez que beneficia também trabalhadores formais.

Dessa forma, pode-se dizer que o Bolsa Famí- 
lia atua como um mecanismo de transferência de renda vertical. Como visto anteriormente, a partir 2002, observa-se o aumento da parcela de renda apropriada pelos $50 \%$ mais pobres e a redução da parcela de renda apropriada pelos $10 \%$ mais ricos (NERI, 2006). Assim, acredita-se que o PBF é um dos fatores que pode ter contribuído para aumentar a renda da população mais pobre e reduzir a desigualdade de renda no Brasil após 2002 (HOFFMANN, 2006; BARROS et al., 2006a; SOARES et al., 2006). Podemos dizer, portanto, que, no que se refere à cobertura, o PBF, enquanto consolidador de um novo pilar da Seguridade Social, por ser uma política não contributiva, exerce papel distinto das políticas de seguro social contributivas. Se, por um lado, o seguro social é focado em situações de ausência de renda, em função de impossibilidade de trabalho, por outro lado, os programas assistenciais não contributivos visam lidar com situações em que já há pobreza instaurada (JACCOUD et al., 2009).

Os dados parecem indicar que as transferências de renda bem focalizadas, de um lado, apresentam grande potencial para reduzir a desigualdade de renda e, de outro, representam um percentual pequeno do PIB. No entanto, no caso do Bolsa Família, que é vinculado a um orçamento predefinido, há uma deficiência na cobertura, ou seja, nem todos aqueles que necessitam recebem o benefício, devido às restrições orçamentárias. Nesse sentido, discute-se se a prioridade seria atender aos elegíveis ou aumentar o benefício para as famílias já cobertas (ROCHA, 2011). Acredita-se que o maior desafio do programa atualmente seja atender a todos aqueles que precisam. Para tanto, é imprescindível que o Programa seja visto enquanto um direito, garantido constitucionalmente.

Além disso, é importante observar que o aumento do valor e do número de benefícios assistenciais não tem sido acompanhado pelo aumento do gasto em investimento social, o que seria essencial para o enfrentamento da nossa desigualdade, vista enquanto um fenômeno crônico. Nesse sentido, questiona-se o potencial de tal política no sentido de garantir a sustentabilidade e a superação do padrão irreversível da desigualdade brasileira (LAVINAS, 2006). O grande investimento nas transferências, apesar de elevar a renda de determinados grupos, se não for acompanhado pelo investimento em outras áreas, acaba por gerar uma integração marginal e precária da pobreza e criar um grupo de "integrados", mantidos em uma situação de "mera reprodução" (SILVA, 2010). Nesse sentido, é importante considerar que o enfrentamento da desigualdade deve envolver ações em áreas como habitação e saneamento, que tem ocupado pouco espaço nos orçamentos públicos (LAVINAS, 2006). Além disso, o gasto com educação, em especial no que se refere ao ensino fundamental, pré-escola e creche, revela uma diminuição per capita no nível municipal. $\mathrm{O}$ investimento nessas áreas torna-se central em termos de sustentabilidade da política social, principalmente em um momento em que se observa a expansão das transferências de renda (LAVINAS, 2006). Observa-se que apesar dos resultados positivos em termos de focalização e de redução dos níveis de desigualdade, o programa não tem estimulado de forma significativa a acumulação de capital humano das novas gerações (SOUZA, 2011).

A análise da política assistencial no Brasil nos permite concluir que esse campo da proteção social brasileira era quase inexistente no período pré CF-88, sendo seus efeitos redistributivos muito limitados. Entretanto, os princípios estabelecidos pelo texto constitucional, tais como a solidariedade nacional e os direitos universais, e o reconhecimento da Assistência Social enquanto uma política pública, representam um avanço no que se refere à busca de uma sociedade mais igualitária, por meio das políticas assistenciais. Os programas de transferência de renda e a estrutura de 
prestação de serviços assistenciais, consolidados após 1988, têm contribuído para a construção de uma Assistência Social mais integrada e eficaz no combate à pobreza e a desigualdade de renda. No entanto, ainda há grandes desafios. A política assistencial brasileira tem caminhado cada vez mais no sentido da focalização. O grande investimento em políticas de transferência de renda focalizadas pode ser efetivo a curto prazo, no que se refere à elevação da renda dos mais pobres. No entanto, tais políticas sozinhas não são capazes de alterar o caráter estrutural da desigualdade brasileira, se não vierem acompanhadas por investimentos em áreas como habitação, saneamento ou educação básica.

\section{CONSIDERAÇÕES FINAIS}

As políticas de Previdência e Assistência Social, enquanto parte de um sistema amplo de proteção social, assumem, frente à precariedade do mercado de trabalho brasileiro, um papel fundamental para a realidade desigual do país. As inovações trazidas pela CF/88 fizeram com que a proteção social brasileira abandonasse o paradigma estritamente contributivo, pois estabeleceu mais dois paradigmas: o não contributivo/seletivo e o universal.

No campo previdenciário, observa-se um caráter perverso, pois, ao mesmo tempo em que há um avanço na ampliação da cobertura e superação da cidadania regulada após 1988, minimizando a desigualdade de renda, o sistema também contribui para a reprodução e o aumento das desigualdades presentes na sociedade. Ressalta-se que a análise da política previdenciária no Brasil nos remete à situação do mercado de trabalho. Dentre os não contribuintes da Previdência Social, a maior parte consiste em trabalhadores que se encontram no mercado de trabalho informal.
Reforça-se, portanto, a ideia de que um modelo previdenciário construído com base no princípio contributivo foi estabelecido em um país onde a sociedade salarial nunca se realizou. Dessa forma, mais do que buscar uma reforma no sistema previdenciário, é necessário refletir sobre a situação atual do mercado de trabalho brasileiro, que se configura como o cerne da questão previdenciária no país.

Portanto, o maior desafio da Previdência Social no Brasil ainda é o alto grau de informalidade que caracteriza o mercado de trabalho. Enquanto parte da população estiver desprotegida contra o risco da perda da capacidade do trabalho, a Previdência continuará contribuindo para a reprodução da desigualdade. Nesse sentido, é necessário que a política previdenciária venha acompanhada de uma política efetiva de geração de empregos formais. Além disso, é necessário repensar a estrutura previdenciária brasileira, que, muitas vezes, acaba por privilegiar uma parcela da população, em especial os empregados no setor público.

Em relação à Assistência Social no período posterior à CF/88, vimos que ela também contribui para a superação da cidadania regulada, uma vez que é uma política não contributiva e destina-se a todos os que dela necessitam. Sendo assim, podemos dizer que a política assistencial, juntamente com a Previdência Social, a saúde e a educação, fazem com que tenhamos hoje no Brasil uma proteção social que atinge a totalidade da população, ainda que existam limitações e grandes desafios para cada uma dessas políticas.

Em especial a partir de 1988, com o reconhecimento da Assistência Social enquanto uma política pública baseada no princípio de solidariedade e não em contribuição, reforça-se o seu papel de combate à pobreza e à desigualdade. As políticas de transferência de renda não contributivas recentemente adotadas vêm contribuindo, em certa medida, para o aumento da renda da parcela mais pobre da população. Entretanto, a 
necessidade de aumento da cobertura e do valor do benefício do PBF tem sido muito discutida. De acordo com dados da PNAD, em 2006 existiam 21,7 milhões de pessoas vivendo em situação de indigência, ou seja, com renda familiar per capita mensal inferior a um quarto do salário mínimo (JACCOUD, 2009). Nesse sentido, o baixo valor do benefício e a deficiência de cobertura ainda constituem desafios para o enfrentamento da indigência no Brasil. Assim, considera-se que elevar o valor médio do benefício e transformá-lo em um direito garantido constitucionalmente sejam passos essenciais no enfrentamento da pobreza e da desigualdade de renda no Brasil, no sentido de buscar uma maior cobertura e sustentabilidade da política, bem como evitar o seu uso político.

Além disso, observa-se que o grande investimento nas políticas de transferência de renda nas últimas décadas revela uma tendência de "superfocalização" do sistema de proteção social brasileiro. Essa estratégia pode ser eficiente no combate à pobreza e à desigualdade a curto prazo. No entanto, tendo em vista que a pobreza é um fenômeno multidimensional e a desigualdade de renda, um problema crônico em nossa sociedade, para que se possa garantir a sustentabilidade das políticas sociais é preciso que haja um aumento nos investimentos em outras áreas, como habitação, saneamento e educação básica.

Observa-se, portanto, que a proliferação dos benefícios previdenciários, aliada aos serviços e benefícios assistenciais, se revelou como necessária à adaptação do modelo de proteção social à estrutura socioeconômica brasileira. As políticas de proteção social têm a capacidade de reduzir as desigualdades presentes na sociedade, mas podem também assumir o efeito inverso e reproduzir ou aumentar essas desigualdades. No Brasil, observa-se que o mercado de trabalho se configura enquanto um entrave para o avanço de tais políticas e, consequentemente, enquanto gerador e reprodutor de desigualdade. Assim, argumenta- -se a favor da tendência de crescimento da proteção social, mas ressalta-se que, para que tenhamos um sistema de proteção social efetivo no sentido de diminuir as desigualdades, é preciso corrigir seus efeitos perversos. Além disso, para que a proteção social tenha um efeito significativo no sentido de gerar uma sociedade menos desigual, tais políticas não podem vir desvinculadas de uma política efetiva de geração de empregos formais e renda, bem como de políticas de habitação, saneamento e educação básica.

\section{NOTAS}

${ }^{1}$ As políticas implementadas por Bismarck na Alemanha durante a década de 1880 podem ser consideradas como precursoras do Estado de Bem-Estar Social e são caracterizadas pelo seu caráter seletivo ou corporativo e pelo esforço em pacificar as forças operárias.

${ }^{2}$ Em certa medida, toda a população contribuía para o sistema, por meio dos impostos indiretos sobre produtos. O Estado, por sua vez, utilizava esses recursos para financiar benefícios e serviços previdenciários, que cobriam apenas os trabalhadores vinculados a algum IAP. Nesse sentido, os "pré-cidadãos" contribuíam indiretamente para o sistema previdenciário, mas não recebiam nenhum tipo de benefício ou serviço.

${ }^{3} \mathrm{O}$ segurado especial é o trabalhador rural, que vive sob o regime de economia familiar.

${ }^{4} \mathrm{O}$ modelo beveridgiano de Estado de Bem-Estar é baseado no então denominado Plano Beveridge, que foi proposto de modo a sugerir a criação de uma rede de seguridade social mais ampla, baseando-se em benefícios universais e uniformes.

${ }^{5}$ Havia a possibilidade de que os servidores recebessem um
aumento no momento da aposentadoria, o que resultou em
benefícios maiores que os salários quando da ativa.

${ }^{6}$ Ainda existem servidores que se beneficiam das regras antigas, resultando num estoque de benefícios incoerente com o fluxo de caixa.

${ }^{7}$ Há uma linha de pobreza extrema, sendo os que se encontram abaixo dela considerados elegíveis ao programa e podendo receber um benefício fixo, mais um adicional variável de acordo com o número de crianças. Já aqueles que se encontram acima da linha de pobreza extrema, mas abaixo da linha de pobreza não extrema, podem receber apenas um benefício variável, de acordo com o número de crianças de 0 a 15 anos, até um máximo de três crianças por família. A partir de julho de 2008, foi também 
implementado outro benefício variável, de acordo com o número de adolescentes entre 16 e 17 anos.

\section{REFERÊNCIAS}

AURELIANO, L.; DRAIBE, S. M. A especificidade do "Welfare State" brasileiro. Brasília, 1989.

BARROS, R. P. et al. Importância da queda recente da desigualdade para a pobreza. In: BARROS, R. P.; FOGUEL, M. N.; ULYSSEA, G. (Orgs.). Desigualdade de renda no Brasil: uma análise da queda recente. Brasília: Ipea, 2006a.

A queda recente da desigualdade de renda no Brasil. In: BARROS, R. P.; FOGUEL, M. N.; ULYSSEA, G. (Orgs.). Desigualdade de renda no Brasil: uma análise da queda recente. Brasília: Ipea, 2006b.

BOSCHETTI, I. Seguridade social e trabalho: paradoxos na construção das políticas de Previdência e Assistência Social no Brasil. Brasília: Letras Livraria/UnB, 2006.

BRASIL. Constituição da República Federativa do Brasil, 1988.

CARDOSO JR., J. C.; JACCOUD, L. Políticas sociais no Brasil: organização, abrangência e tensões da ação estatal. In: JACCOUD, L. (Org.). Questão social e políticas sociais no Brasil contemporâneo. Brasília: Ipea, 2005.

DELGADO et al. Seguridade social: redefinindo o alcance da cidadania. In: Políticas sociais: acompanhamento e análise. Vinte anos da Constituição Federal. Brasília: Ipea, 2009.

ESPING-ANDERSEN, G. The Three Worlds of Welfare Capitalism. Princeton, NJ: Princeton University Press, 1990.

FERREIRA, C. R.; SOUZA, S. C. I. "Aposentadorias e pensões" e desigualdade da renda: uma análise para o Brasil no período 1998-2003. Revista de Economia Contemporânea, v. 12, n. 1, p. 41-66. Rio de Janeiro, 2008

FERREIRA, F. H. G. et al. Ascensão e queda da desigualdade de renda no Brasil: uma atualização para 2005. In: BARROS, R. P.; FOGUEL, M. N.; ULYSSEA, G. (Orgs.). Desigualdade de renda no Brasil: uma análise da queda recente. Brasília: Ipea, 2006.

GIAMBIAGI, F; ALÉM, A. C. Finanças públicas: teoria e prática no Brasil. Rio de Janeiro: Campus, 1999. Cap. 8: A crise da Previdência Social, p. 211-241.

HOFFMANN, R. Queda da desigualdade da distribuição de renda no Brasil, de 1995 a 2005, e delimitação dos relativamente ricos em 2005. In: BARROS, R. P.; FOGUEL, M. N.; ULYSSEA, G. (Orgs.). Desigualdade de renda no Brasil: uma análise da queda recente. Brasília: Ipea, 2006.

Desigualdade da distribuição da renda no Brasil: a contribuição de aposentadorias e pensões e de outras parcelas do rendimento domiciliar per capita. Economia e Sociedade, Campinas, v. 18 , n. 1, p. $213-231,2009$

Desigualdade da renda e das despesas per capita no Brasil, em 2002-2003 e 2008-2009, e avaliação do grau de progressividade ou regressividade de parcelas da renda familiar. Economia e Sociedade, Campinas, v. 19, n. 3 (40), p. 647-661, dez. 2010

IPEA. Políticas Sociais. Assistência Social e Segurança Alimentar. Edição Especial, 2007.

A queda recente da desigualdade no Brasil. Brasília, 2006. (Nota técnica).

IPEADATA. Disponível em: <www.ipeadata.gov.br>. Acesso em: 20 jun. 2012.

JACCOUD, L. Pobres, pobreza e cidadania: os desafios recentes da proteção social. Brasília: Ipea, 2009. (Texto para Discussão n ${ }^{0}$ 1373).

JACCOUD, L. et al. Assistência social e segurança alimentar: entre novas trajetórias, velhas agendas e recentes desafios (1988-2008). In: Políticas sociais: acompanhamento e análise - Vinte anos da Constituição Federal. V. 1, nº 17. Brasília: Ipea, 2009.

LAVINAS, L. Transferências de renda: o "quase tudo" do sistema de proteção social brasileiro. In: Encontro Nacional da Associação Nacional dos Centros de Pós-Graduação em Economia, 34, 2006, Anais... ANPEC, 2006

MAIA, A. G. A contribuição das fontes de rendimento da dinâmica da distribuição espacial de renda no Brasil. Nova Economia, Belo Horizonte, set./dez. 2010

MDS. Ministério do Desenvolvimento Social e Combate à Fome. Disponível em: <www.mds.gov.br>. Acesso em: 20 jun. 2012.

NERI, M. A dinâmica da redistribuição trabalhista. In: BARROS, R. P.; FOGUEL, M. N.; UlYSSEA, G. (Orgs.). Desigualdade de renda no Brasil: uma análise da queda recente. Brasília: Ipea, 2006.

Desigualdade de renda na década. Centro de Políticas Sociais, Fundação Getulio Vargas, 2011. Disponível em: <http:// www.cps.fgv.br/cps/bd/DD/DD_Neri_Fgv_TextoFim3.pdf $>$. Acesso em: 21 jun. 2012

RAMOS, L. Desigualdade de rendimentos do trabalho no Brasil, de 1995 a 2005. In: BARROS, R. P.; FOGUEL, M. N.; ULYSSEA G. (Orgs.). Desigualdade de renda no Brasil: uma análise da queda recente. Brasília: Ipea, 2006.

RAMOS, L.; VIEIRA, M. L. Desigualdade de rendimentos no Brasil nas décadas de 1980 e 1990: evolução e principais determinantes. Brasília: Ipea, 2001. (Texto para Discussão no 803).

RANGEL et al. Conquistas, desafios e perspectivas da Previdência Social no Brasil vinte anos após a promulgação da Constituição 
Federal de 1988. In: Políticas sociais: acompanhamento e análise. Vinte anos da Constituição Federal. Brasília: Ipea, 2009.

ROCHA, S. Os "novos" programas de transferências de renda: impactos possíveis sobre a desigualdade no Brasil. In: BARROS, R. P.; FOGUEL, M. N.; UlYSSEA, G. (Orgs.). Desigualdade de renda no Brasil: uma análise da queda recente. Brasília: Ipea, 2006.

O Programa Bolsa Família. Evolução e efeitos sobre a pobreza. Economia e Sociedade, Campinas, v. 20, n. 1 (41), p. 113-139, abr. 2011.

SABOIA, J. O salário mínimo e seu potencial para a melhoria da distribuição de renda no Brasil. In: BARROS, R. P.; FOGUEL, M. N.; ULYSSEA, G. (Orgs.). Desigualdade de renda no Brasil: uma análise da queda recente. Brasília: Ipea, 2006.

SANTOS, W. G. Cidadania e justiça: a política social na ordem pública brasileira. Rio de Janeiro: 1979.

SILVA, M. O. S. Pobreza, desigualdade e políticas públicas: caracterizando e problematizando a realidade brasileira. Katalysis, Florianópolis, v. 13, n. 2, p. 155-163, jul./dez. 2010.
SOARES, F. V. et al. Programas de transferência de renda no Brasil: impactos sobre a desigualdade. Brasília: Ipea, 2006. (Texto para Discussão $n^{\circ} 1228$ ).

SOARES, S.; SÁTYRO, N. O Programa Bolsa Família: desenho institucional, impactos e possibilidades futuras. Brasília: Ipea, 2009. (Texto para Discussão no 1424).

SOUZA, A. P. Políticas de distribuição de renda no Brasil e o Bolsa Família. São Paulo: Escola de Economia de São Paulo, Fundação Getulio Vargas, 2011. (Texto para Discussão n 281).

TITMUSS, R. M. Social Policy: An Introduction. London: 1974.

VIANNA, M. L. T. W. A americanização (perversa) da seguridade social no Brasil: estratégias de bem-estar e políticas públicas. Rio de Janeiro: Revan, Ucam, Iuperj, 1998. 